Features

\title{
Importance of Horticulture and Perception as a Career
}

\author{
Mary H. Meyer ${ }^{1,6}$, Douglas Needham ${ }^{2}$, John Dole ${ }^{3}$, \\ Brain Trader ${ }^{2,3}$, Jennifer Fox ${ }^{2}$, Marnie Conley ${ }^{2}$, Michael Neff $^{4}$, \\ and Jean Shaw ${ }^{5}$
}

ADDITIONAL INDEX WORDs. youth, employment, students, enrollment, jobs

Summary. The American Society for Horticultural Science (Alexandria, VA) and Longwood Gardens (Kennett Square, PA) engaged FleishmanHillard (FH, Washington, DC), a nationally recognized communications and marketing firm, to conduct research with internal and external audiences to determine the public perception of horticulture and careers in horticulture. Through stakeholder focus groups and general public online and phone surveys, the importance of horticulture, career perceptions, and the need for the promotion of horticulture were examined. Students, faculty, industry, and administrators in horticulture have a broad understanding of the field, much more than the public, especially young, ethnically diverse, and lower income participants. Although lack of public awareness is one of the biggest challenges in horticulture, it is also its greatest opportunity. Sixty-five percent of all phone survey participants as compared with $41 \%$ of 18-24 years old revealed a general awareness of the word horticulture. General public found agreement $(48 \%$ to $59 \%)$ with four statements about the essential, universal, and invaluable worth of horticulture; however, strong agreement was less, ranging from $26 \%$ to $46 \%$. Only $26 \%$ of respondents felt strong agreement with the statement, "Horticulture is a diverse area of study, and it offers viable, fulfilling, and respected career paths that I would recommend to others.” The research found strong stakeholder support for a national promotion of horticulture.

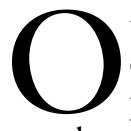

ur world is highly dependent on horticultural expertise to provide the technology and people necessary to meet the rapidly increasing global demand for fruits,

\footnotetext{
${ }^{1}$ Department of Horticultural Science, University of Minnesota, Saint Paul, MN 55318

${ }^{2}$ Longwood Gardens, Kennett Square, PA 19348

${ }^{3}$ Department of Horticultural Science, North Carolina State University, Raleigh, NC 27607

${ }^{4}$ American Society for Horticultural Science, Alexandria, VA 22314

${ }^{5}$ FleishmanHillard, Saint Louis, MO 63102

${ }^{6}$ Corresponding author. E-mail: meyer023@umn.edu.

This is an open access article distributed under the CC BY-NC-ND license (http://creativecommons.org/ licenses/by-nc-nd/4.0/).
}

vegetables, nuts, herbs, and ornamentals in the face of the changing global environment and limited natural and financial resources (Siegel et al., 2014). Horticultural science is critical in improving the nutritional content of food, enhancing the safety of our produce supply, and increasing the availability of healthy, local, and sustainably produced foods (Rubatzky et al., 2012). In addition, the role that horticulture plays in promoting positive mental well-being, on a large scale from public botanic gardens, parks, and sports fields, to small-scale individual home gardens is critical to our life today (Hall and Dickson, 2011).
Despite the increasing value of commercial horticulture crops and services (U.S. Department of Agriculture, 2009) university horticulture programs have plateaued or experienced declining student enrollment, with only $31 \%$ of 4 -year schools indicating the word "horticulture" was still in their department title (Dole, 2015). Arnold et al. (2014) surveyed graduate programs, showing enrollment declined in 39\% of MS and $31 \%$ of $\mathrm{PhD}$ programs at land-grant universities in the last 5 years, whereas $21 \%$ and $27 \%$ of programs increased and $23 \%$ and $41 \%$ were steady, respectively, for MS and PhD programs.

Jobs in horticulture are available: an average of 35,400 new U.S. graduates with expertise in food, agriculture, renewable natural resources, or the environment, are expected to fill only $61 \%$ of the expected 57,900 average annual openings (Goecker et al., 2015). Concurrently, the horticulture industry shows a shortage of trained professionals with a gap between students graduating and employees needed for many areas of horticulture (Dickey, 2014; Needleman, 2014).

The perception of horticulture is often limited (Higgins, 2014) and increasingly negative (Smith, 2014). Plant blindness, defined as "the inability to see or notice the plants in one's own environment, leading to the inability to recognize the importance of plants in the biosphere and in human affairs" (Wandersee and Schussler, 2001) along with more than $53 \mathrm{~h}$ per week in screen time (Kaiser Family Foundation, 2010) and only half as much time outdoors for young people (Juster et al., 2004) have affected the perception of plants and reduced children's interaction with plants and their choice of careers involving plants.

Limited awareness of horticulture and insufficiently trained employees are not localized to the United States. In Australia, the government developed specific strategies to promote horticulture (Collins and Dunne, 2009; McEvilly and Aldous, 2010), perhaps based on an earlier comment: "The horticultural industry does not effectively and positively sell itself generally to the broader community, and more specifically to parents, guidance officers/career counselors 
and students. A whole-of-horticulture promotional/public relations campaign is clearly needed to achieve this purpose" (Stone et al., 2005). In Britain, the Royal Horticultural Society (RHS) used a collaborative approach involving parliament and industry documented in Horticulture Matters, but still reported $70 \%$ of horticultural businesses struggled to fill skilled vacancies (RHS, 2015). The International Society for Horticultural Science also addressed the importance of horticulture and its diverse career options in its publication (Hewett et al., 2012).

Leadership in American Society for Horticulture Science (ASHS) and Longwood Gardens realized the limited public, especially youth, awareness of horticulture and careers in horticulture and the lack of trained professionals. Several horticultural administrators at land-grant universities also recognized this limited perception and agreed to financially support this initiative. To better understand the public perception and importance of horticulture, the challenges the industry is facing, and the various paths individuals take to get into the field, ASHS and Longwood Gardens engaged FH to conduct qualitative and quantitative research with internal and external audiences as a first step to addressing these issues.

\section{Materials and methods}

Qualitative, informal, and intercept interviews were conducted by FH at the July 2014 Cultivate' 14 trade show and conference (AmericanHort, Columbus, OH). Participants included current horticulture students, young professionals [e.g., 40 under 40 (Fortune magazine's recognition of emerging leaders under 40 years of age); Unplugged (young professionals networking event at Cultivate'15)], academics and industry professionals [e.g., American Floral Endowment (Alexandria, VA); and Florasearch (Sanford, FL)]. Intercept survey information was not extensive enough to draw conclusions, but was used to formulate the questions for the subsequent focus groups and online and phone surveys.

A formal focus group was conducted in Columbus, $\mathrm{OH}$, with 26 garden educators and coordinators at the July 2014 National
Children \& Youth Garden Symposium (NCYGS), sponsored by the American Horticultural Society (AHS, Alexandria, VA). Registrants were solicited by e-mail and on site during the conference to participate in the 2$h$ focus group. The final five focus groups were conducted in Miami, FL, at the July 2014 ASHS Annual Conference with current horticulture undergraduate students $(\mathrm{n}=$ $7)$, graduate students $(n=8)$, industry leaders $(\mathrm{n}=6)$, faculty $(\mathrm{n}=$ $7)$, and university administrators ( $\mathrm{n}=$ $5)$. Registrants were solicited via e-mail and during the conference to attend the 2 -h focus groups.

Focus group discussions were informal, with one person asking questions to the group that participants could answer at will. Focus group questions were divided into three sections: importance of horticulture, horticultural careers, and promotion of horticulture, with 610 questions per section. Selected, key questions were as follows: Horticulture Importance: Why is horticulture important? How does horticulture benefit society? What is the public's perception of horticulture? What do you consider to be the biggest challenges facing the horticulture industry? Careers: When did you first start considering horticulture as a career field? How did you first learn about it? What concerns, if any, did you have about pursuing a career in horticulture? What do you believe are the biggest benefits of this career field? Why would you recommend students to consider horticulture as a career field/area of study? For what reasons, if any, would a student not choose horticulture as a career field/ area of study? Promotion: This initiative will focus on middle- and highschool students; what do you perceive as the biggest challenge in reaching this audience? In reaching and motivating this audience, what role do you think industry should play?

An online survey was developed by ASHS and FH and was open to anyone with the URL, but was promoted primarily to horticulture stakeholders at conferences and presentations from June through Oct. 2014 (ASHS, 2014) and was removed in early 2015. The online survey consisted of four open-ended questions: 1) Why should the general public care about horticulture?
2) What do you consider to be the biggest challenges facing the horticulture industry? 3) Why would you recommend horticulture as a career field to students/youth? 4) In reaching and motivating high-school students to become interested in horticulture, what role do you think the industry should play?

In June 2015, an omnibus phone survey was conducted by ORC International (Princeton, NJ) for $\mathrm{FH}$ to obtain a baseline measure of the broader U.S. public's awareness and perceptions of horticulture. The study was conducted using two probability samples: 509 randomly selected landline telephone numbers and 500 randomly selected mobile (cell) telephone numbers. The combined sample consisted of 1009 adults (18 years and older) living in the continental United States and representative of the U.S. adult population. The margin of error for the sample of 1009 was $\pm 3.09 \%$ at the 95\% confidence level. Smaller subgroups had larger error margins.

Phone participants were asked to respond to four questions: 1) Before today were you familiar with the word horticulture? 2) How would you define horticulture (openended question)? 3) How much do you agree with the following definition of horticulture? "As you may or may not know horticulture is the art, science, production, business and use of fruits, vegetables, flowers and ornamental plants. This could mean food and nutritional plants including fruits, vegetables, mushrooms, and culinary herbs. Or it could mean non-food plants such as flowers, trees, turf-grass, hops, and shrubs. Both food and non-food uses have applications in small businesses as well as large corporations. And both can greatly impact our health and well-being"; and 4) participants were asked how much they agreed or disagreed with four statements about horticulture (Fig. 1).

\section{Results}

A total of 59 people participated in the six focus groups at the AHS and ASHS conferences. The online survey received 511 usable responses, whereas the phone survey had 1009 usable responses. Results were compiled into qualitative data from the focus groups and quantitative data 
1. Horticulture is a diverse area of study, and it offers viable, fulfilling and respected career paths that I would recommend to others.

2. Horticulture is a universal omnipresent science and art that is at the core of our physical and emotional well-being through our food and environment.

3. Horticulture is invaluable in that it is everything we eat. It is the plants that surround us. It is all that provides us life and sustains our world.

4. Horticulture is essential to our food, our water and our environment. It is essential to our well-being and the well-being of our children, our communities, our planet and our future.

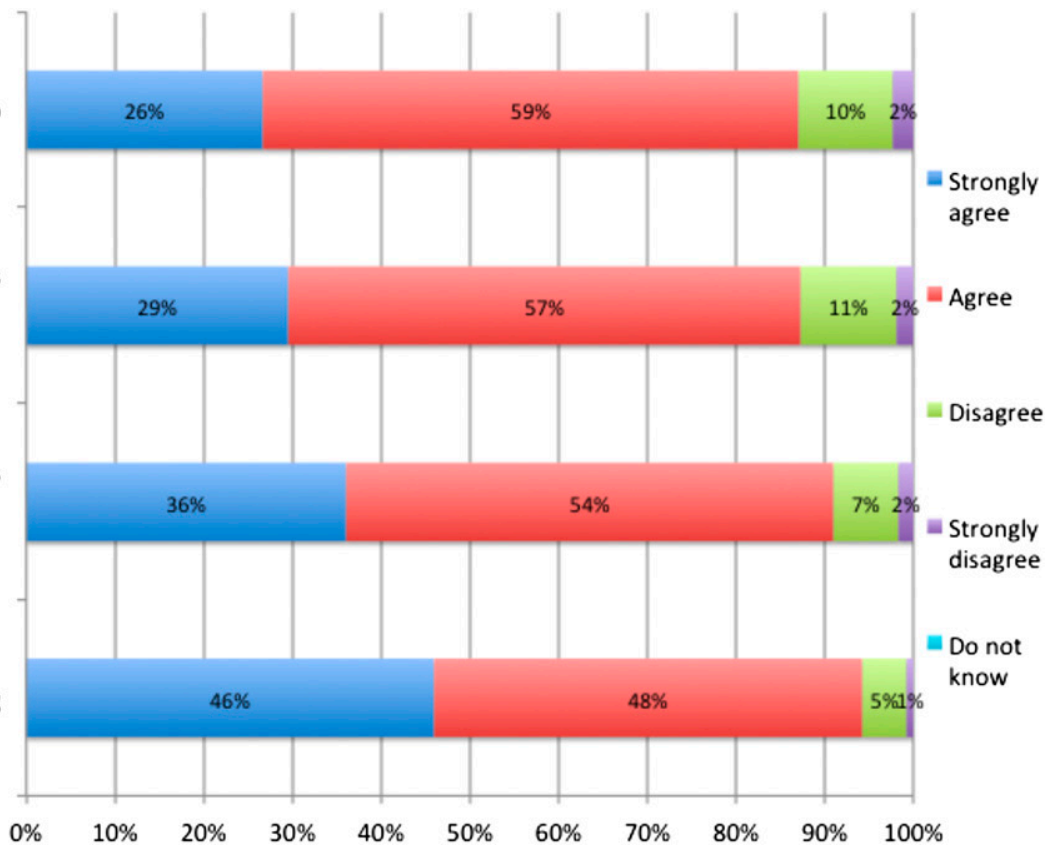

Fig. 1. Participant responses $(n=1009)$ to a general public omnibus phone survey about horticulture when asked: "To what extent do you agree or disagree with the following statements about horticulture?" Statement 1: The smallest number of respondents strongly agreed with this statement; $3 \%$ responded do not know. Statement 2: White respondents were more likely to strongly agree $(32 \%)$ with this statement than Hispanic respondents $(20 \%) ; 2 \%$ responded do not know. Statement 3 : Those $35+$ years old were more likely to strongly agree $(42 \%)$ with this statement than those $18-34$ years old (22\%). White respondents were more likely to agree or strongly agree $(92 \%)$ with this statement than Hispanic respondents $(83 \%)$; $1 \%$ responded do not know. Statement 4 : Those $35+$ years old were more likely to strongly agree $(51 \%)$ with this statement than those 18-34 years old (34\%); and 1\% responded do not know.

from the online and phone surveys. The responses were summarized into three sections: 1) the importance and perception of horticulture, 2) horticulture as a career including engaging youth and challenges facing the industry, and 3 ) the need for a national initiative to promote horticulture.

IMPORTANCE AND PERCEPTION OF HORTICULTURE. All focus groups agreed that horticulture is an extremely important field that is often undervalued and misunderstood; all felt that the public does not fully value and understand horticulture. Participants felt the general public should care about horticulture, because it protects the ecosystem and environment, provides visual aesthetics and places of tranquility to urban areas, helps with conservation, produces food, and connects people to the earth and environment. Specific comments included “It's basically how we maintain our lives. Without it, no food, air, water, anything" (undergraduate student); "Beauty, enjoyment and mental health." (NCYGS participant); "Supply food to one-third of the
American diet. Without horticulture, life would be extremely boring. Just look at sports turf, your diet, how we comfort ourselves during funerals and celebrate life with flowers. It makes life interesting" (administrator). The online survey showed similar responses on the importance of horticulture with health and nutrition benefits showing the highest recognition of $66 \%$ (Table 1 ).

Using the phone survey as a subsample of the U.S. population, it is possible to extrapolate how different demographic segments would respond to the question "Before today were you familiar with the word horticulture" (Table 2 ). When asked about familiarity with the word horticulture, $65 \%$ of phone survey participants indicated yes, whereas 35\% were not or did not know enough to respond positively. When examined by age category within the $65 \%$ who indicated yes they were familiar with the word horticulture, $57 \%$ were $30-$ 34 years old, $50 \%$ were $25-29$ years old, and only $41 \%$ of $18-24$ years old respondents indicated they were familiar with the word horticulture.
Table 1. Participant responses to a public online survey promoted to horticulture stakeholders from June through Oct. 2014, to the question: "Why should the general public care about horticulture?" $(n=488)$.

\begin{tabular}{lc}
\hline Benefit cited & Responses (\%) \\
\hline Health/nutritional & 66 \\
Educational & 43 \\
Aesthetic & 43 \\
Environmental & 35 \\
Relationship with nature & 29 \\
\hline
\end{tabular}

Although not statistically significant, awareness tends to trend lower with younger Americans.

When asked to define horticulture (open-ended question), 86\% of respondents said it involved plant growth or care; $46 \%$ mentioned cultivating, planting, growing, or caring for plants; $35 \%$ said horticulture was related to plants or the science and study of plants; and $21 \%$ said horticulture was gardening. After hearing a definition of horticulture (see methods and materials above), $41 \%$ responded that it was "a lot" in 
Table 2. Extrapolated responses to reflect the U.S. population by demographic based on a June 2015 general public omnibus phone survey about horticulture. The survey question was: "Before today were you familiar with the word horticulture?" $(n=1009)$.

\begin{tabular}{lc}
\hline Demographic & $\begin{array}{c}\text { Respondents } \\
\text { familiar with } \\
\text { the word } \\
\text { "horticulture" (\%) }\end{array}$ \\
\hline 18 to 34 years old & 48 \\
35+ years old & 72 \\
Caucasian & 76 \\
African American & 49 \\
Hispanic & 41 \\
$<$ \$50,000 Income & 54 \\
>550,000 Income & 78 \\
College degree & 80 \\
Some college & 71 \\
High school or less & 52 \\
\hline
\end{tabular}

alignment with their personal understanding; 36\% said "somewhat," $10 \%$ said "not much" and 7\% said "not at all." Those $35+$ years of age were more likely to say the definition aligned a lot or somewhat $(81 \%)$ with their understanding than those 18-34 years old $(67 \%)$. White respondents were more likely to say the definition aligns a lot or somewhat $(82 \%)$ with their understanding than Hispanic respondents $(68 \%)$. U.S. adults with a college degree $(84 \%)$ or some college education $(80 \%)$ were more likely to say the definition aligns a lot or somewhat with their understanding than those with a high school education or less $(70 \%)$. The phone survey found agreement $(48 \%$ to $59 \%)$ with three statements about the essential, universal, and invaluable worth of horticulture; however, strong agreement was less, ranging from $29 \%$ to $46 \%$ (Fig. 1).

HORTICUlTURe AS A CAREer. Individuals found horticulture through a number of different paths, but often it started with a garden. While some individuals were exposed to horticulture at a young age through a family garden, others were drawn because of their interest in science. Some of the focus group responses to questions about how they found horticulture were: "Ever since I could remember, I was in a garden, helping my grandfather" (undergraduate student); "Fifth grade. A teacher explained nature well and explained that they could make a career in it" (NCYGS participant); "For me, it was my first veggie garden. I was 24 . It was the first thing in my life that I loved doing. I started looking for careers I could have that would help me work with plants" (undergraduate student); "I gardened with my grandma. I'd rather be outside. The desire to be outside and being interactive" (undergraduate student).

Once individuals discovered horticulture, they also realized a number of attributes that made it an appealing profession: job availability, work outside; creative, artistic; innovation, technology related; and the work could impact the world, environment. Comments from focus group participants were: "As a kid, I did Boy Scouts, things to do with nature. I had friends in high school that did Future Farmers of America, (FFA). That was my first exposure. As an undergrad, I was pre-dental. I was two years in and getting really bored. I took horticulture as an elective. I discovered that there's research and development. They have marketing, all these different parts of the business. I realized I could have a career here that it's not just farming. That peaked my interest" (graduate student); "One of the driving factors was that I knew there would be jobs in this industry" (graduate student); "There are so many technologyrelated things in horticulture that don't come to mind immediately to people. High tech greenhouses, light-emitting diode (LED)" (industry); "People need to realize they can make a difference through horticulture, even if they aren't making as much money" (NCYGS participant); "Most seniors have between five and 10 job offers. How many other fields can say that. There are constant opportunities" (undergraduate student).

Online survey participants felt rewarding and satisfying work, diversity of jobs, and the ability to work outside were reasons to recommend horticulture as a career (Table 3). Low pay was the most cited reason for not recommending horticulture as a career $(66 \%)$, followed by negative working conditions $(27 \%)$ (Table 4$)$.

Focus group participants perceived similar drawbacks to pursuing a horticulture career: low pay, yet even this was debated because there is such a wide range of jobs available. “The profession doesn't make nearly as much money as other industries, but it is important and people love it" (NCYGS participant). "It's more than just plants and public gardens" (undergraduate student). "My concern is that I'm never going to make good money. I'll be relegated to less than \$15 per hour. I'd rather not make a lot of money and love my life" (undergraduate student).

Only $26 \%$ of phone survey respondents felt strong agreement with the statement of viable horticultural careers that they would recommend to others; however, $59 \%$ of respondents did agree with this statement (Fig. 1).

E NGA G I N G Y OU TH I N HORTICULTURE. Focus group stakeholders felt there were a number of factors that make horticulture a desirable profession, which should be used when encouraging others to consider the field. They felt that better communicating the advantages, such as job availability, creative and artistic outlet, working outside, and impacting the world, would help to attract the next generation of horticulturists. "Show them there's a lot to do. Wide range of jobs. If you get in this career, you have a bunch of doors open. You can be a teacher, researcher, working for the industry" (graduate student). "Anything to do with growing food is job security. Wanting to make a difference. And the idea that they're dealing with plants" (industry). "People need to realize that horticulture is a real profession that they could do. They don't see it as work" (NCYGS participant). "You can be your own boss. You can be outside. You can be creative and an entrepreneur" (NCYGS participant). "They're interested in nutrition, sustainability, environment, genetics, but they're starting to understand we'll have to feed more people. So we're starting to get them for other reasons" (administrator). "People need to know that it can be a lucrative career. Horticulture doesn't mean you'll be poor for the rest of your life" (undergraduate student).

Online survey respondents recognized the importance and need of engaging youth in horticulture as well as ways to successfully get youth interested in horticulture: $33 \%$ cited 
Table 3. Participant responses to a public online survey promoted to horticulture stakeholders from June through Oct. 2014, to the question: "Why would you recommend horticulture as a career field to students/youth?" $(n=482)$.

Reason for recommending horticulture Responses (\%)

Rewarding can see quick results, 28 satisfying work, making a difference, and fulfilling

Diverse, variety, and range of careers available

Ability to work outside and working with nature

Good for the community, helping others, and can help feed others

Impacting the world, environment, and improving the environment

Interest in plants, like working with plants, and pleasure in working in nature

Growing opportunities and many job opportunities

Learning opportunities, good knowledge to have, and many skills learned

Enjoyment and fun work

Ability to be creative and to create

Good for health and being active

Good career field and positive (general)

Needed and always will need plants

Table 4. Participant responses to a public online survey promoted to horticulture stakeholders from June through Oct. 2014, to the question: "For what reasons, if any, would a student not choose horticulture as a career field?" $(n=481)$.

\section{Reason}

Low pay, money, financial reasons

Responses (\%)

Physically demanding, hard work, have to

be a hard worker, and work long hours

Lack of interest and/or knowledge and no interest in plants

Bad image, lack of industry support, no respect, and not seen as professional

Dislike working outdoors, dislike bugs, affected by allergies, and too much sun

Lack of career options and career paths limited

Seasonal work and hard to find work

Dirty work and dislike getting dirty

Poor career field and negative (general)

Table 5. Participant responses to a public online survey promoted to horticulture stakeholders from June through Oct. 2014, to the question: "In your experience, what is most successful at getting youth interested in horticulture?" $(n=480)$.

\begin{tabular}{lc}
\hline Reason & Response (\%) \\
\hline $\begin{array}{l}\text { Gardens, having a garden, watching plants grow, } \\
\text { growing own food, and food production }\end{array}$ & 33 \\
Hands-on experience and getting hands dirty & 31 \\
Early exposure and positive early experiences & 16 \\
Teach about plants, develop knowledge, and awareness & 13 \\
$\quad$ of plants (nonspecific) & 12 \\
Experience, exposure to outdoors, and working in nature (nonspecific) & 9 \\
Integration with school curriculum and programs & 6 \\
Family activities, family engagement, and planting at home & 6 \\
Good mentors and teachers & 5 \\
Involvement in clubs that support and promote horticulture & 5 \\
Field trips and visit or tour gardens & 5 \\
Connection with nature, how nature is related to us, & \\
$\quad$ and how it impacts our lives & 5 \\
Make it fun and make it exciting & 3 \\
Internships, scholarships, and career fairs & \\
\hline
\end{tabular}

gardens, having a garden, watching plants grow, growing own food, food production would engage youth and $31 \%$ suggested hands-on experience, getting hands dirty to interest kids (Table 5). It is interesting to note that $30 \%$ of online survey respondents believe that the industry can play a role in engaging youth by providing internships and scholarships (Table 6) but this role was cited by only $3 \%$ in the previous table. Perhaps internships and scholarships are the traditional means of connecting industry with students and other creative ideas are needed to reach young people.

CHALLENGES FACING THE HORTICULTURE INDUSTRY. Focus group participants indicated the industry is facing a number of challenges: shrinking university programs, consolidation of degree programs, skilled labor shortage, lack of industry leaders and a well-trained workforce, lack of funding and grants, lack of public awareness and understanding, and low pay. The good news is that most everyone felt these challenges could be overcome by increasing public awareness and understanding of the value of horticulture. Stakeholders felt the perceptions of the industry can improve through focus on the benefits, by making horticulturists more visible and showing connections to science and technology. "When people ask what I'm majoring in and I say 'horticulture,' people don't know what it means" (graduate student). "More often than not, they equate what we do with gardening. That's the other end of the spectrum. It's not the science" (administrator). "The word 'horticulture' is disappearing from the university landscape. A lot of people don't know what it is. The stereotype is a shovel in one hand. Now some of the best students are moving into environmental science. That's concerning" (industry). "Industry would say there is a lack of trained labor. Not even basic skills. And we're not turning out enough students to take these jobs. There's not a job shortage in horticulture, there's a pipeline shortage" (faculty). "I think it [consolidated programs] matters. I almost feel deprived. I don't get to lead with a specialty. When you merge with plant sciences, you're even further away from horticulture. It's so much 
Table 6. Participant responses to a public online survey promoted to horticulture stakeholders from June through Oct. 2014, to the question: "In reaching and motivating high-school students to become interested in horticulture, what role do you think the industry should play?" $(n=477)$.

\begin{tabular}{lc}
\hline Industry role & Responses (\%) \\
\hline Internships and scholarships & 30 \\
Provide hands-on opportunities, gardening, and field trips & 28 \\
Educate, teach, and speak with students about horticulture (nonspecific) & 15 \\
Good opportunities, viable career options, and career possibilities & 14 \\
Promote careers and participate in career days (nonspecific) & 13 \\
Support school programs, clubs, workshops, and classes & 12 \\
Provide funding, sponsor, and involvement (nonspecific) & 9 \\
Good mentors and learn from professionals & 7 \\
Partnerships with high schools and outreach & 6 \\
Environmental responsibility, sustainability, and making & 4 \\
$\quad$ improvements in nature & \\
Improve image and more positive exposure & 3 \\
Value to society and making connections to everyday life & 1 \\
\hline
\end{tabular}

Table 7. Participant responses to a public online survey promoted to horticulture stakeholders from June through Oct. 2014, to the question: "What do you consider to be the biggest challenges facing the horticulture industry?" $(n=487)$.

\begin{tabular}{lc}
\hline Challenge & Responses (\%) \\
\hline Education and awareness challenges & 54 \\
Economic challenges & 42 \\
Lack of respect, seen as unskilled labor and anyone can do it & 17 \\
Environmental challenges & 17 \\
Not seen as important, lack of interest, & 9 \\
support, and apathy (nonspecific) & \\
\hline
\end{tabular}

more than plant biology" (undergraduate student).

Online survey participants mentioned similar challenges, $54 \%$ cited education and awareness challenges, whereas $42 \%$ mentioned economic challenges (Table 7). Phone survey participants revealed a general awareness of horticulture, but $35 \%$ were not aware of the word, and the younger the respondent, the more limited their perception $(59 \%$ of $18-24$ years old were not aware of the word), especially for career opportunities.

Promoting horticulture INITIATIVE. Focus group participants were briefly introduced to the idea of a national promotion for horticulture. However, there were different points of view regarding where the initiative should focus its efforts. Public garden professionals tended to recommend starting with elementary-aged children. Others made a strong case for middle- and high-school students. Still, there appears to be an opportunity to reach individuals once they've entered a university. Making people more aware of all the benefits associated there is an increasing need for educated, well-trained students.

A limited awareness of horticulture including the diversity of careers has likely hindered students from pursuing this field of study. When Wandersee and Schussler (2001) studied plant blindness, they found "early and iterative, well-planned, meaningful and mindful education (both scientific and social) about plants - coupled with a variety of personal, guided, direct experiences with growing plants - may be the best way to overcome what we currently see as the human "default condition"plant blindness."

This research found strong support for promoting horticulture, now branded the Seed Your Future campaign. Nearly $100 \%$ of horticulture stakeholders that took part in the focus groups volunteered their support and enthusiasm for the campaign, indicating a great need in the industry. To appeal to youth, it will be important for any promotion of horticulture to present a youthful, fresh face for students in middle and high school, and where possible, elementary school. By showcasing horticulture's innovation with science, technology and the breadth of work taking place across the industry that can impact major, global issues, it is hoped that a new image for and awareness of horticulture can be created. key to growing the profession. Overall, focus group survey respondents support the initiative and want to see stronger youth engagement in horticulture.

\section{Conclusions}

Stakeholders were in agreement that limited public awareness is one of the biggest challenges facing horticulture; participants in the general public phone survey showed 48\% to $59 \%$ agreement and $26 \%$ to $49 \%$ strong agreement with statements about horticulture's importance. Given the number of benefits associated with the industry-available jobs, science/technology, environment and human benefits, working outdoors, etc., all benefits valued by millennials (persons reaching young adulthood around the year 2000) and other youth audiences, communicating these attributes can help pique individuals' interest in the field. Interesting, challenging, and impactful careers are available in horticulture at all levels, and

\section{Literature cited}

American Society for Horticultural Science (ASHS). 2014. GrowIt. 1 Sept. 2014. < growit.ashs.org>.

Arnold, M.A., R.D. Lineberger, T.D. Davis, D.W. Reed, and W.J. McKinley. 2014. A survey of North American horticulture graduate programs: Demographics, policies, finances, and metrics. HortTechnology 24:24l-251.

Collins, R.J. and A.J. Dunne. 2009. Can dual degrees help to arrest the decline in tertiary enrolments in horticulture: A case study from the University of Queensland, Australia. Acta Hort. 832:65-70.

Dickey, M. 2014. NCNLA President's message. Nursery Landscape Notes 84(3):5-7.

Dole, J. 2015. Status of student numbers and program identity at two-year and four-year horticultural programs. ASHS Nwsl. 31(1):5-6.

Goecker, A., E. Smith, J. Marcos Fernandez, R. Ali, and R. Goetz Theller. 2015. 
Employment opportunities for college graduates in food, agriculture, renewable natural resources, and the environment, United States, 2015-2020. 28 Oct. 2015. <https://www.purdue.edu/usda/ employment $/>$.

Hall, C. and M.W. Dickson. 2011. Economic, environmental, and health/wellbeing benefits associated with green industry products and services: A review. J. Environ. Hort. 29:96-103.

Hewett, E., I. Warrington, and C. Hale. 2012. Harvesting the sun-A profile of world horticulture. 23 Oct. 2015. <http://www.ishs.org/scriptahorticulturae/harvesting-sun-profileworld-horticulture $>$.

Higgins, A. 2014. Why we need horticulturists. 12 Dec. 2014. <https://www. washingtonpost.com/lifestyle/home/ why-we-need-horticulturists/2014/12/ $09 /$ a 63 a 152 a - 7 c b $4-11$ e 4 - b 821 503 cc7efed9e_story.html>.

Juster, F.T., H. Ono, and F. Stafford. 2004. Changing times of American youth: 1981-2003. 29 Oct. 2015. <http://ns.
umich.edu/Releases/2004/Nov04/ teen_time_report.pdf $>$.

Kaiser Family Foundation. 2010. Generation M2: Media in the lives of 8-to 18-year-olds. 28 Oct. 2015. <http:// $\mathrm{kff}$.org/other/event/generation-m2media-in-the-lives-of $/>$.

McEvilly, G. and D. Aldous. 2010. Guiding young people to horticulture. Chron. Hort. 50(3):16-18.

Needleman, S. 2014. Skilled labor shortage means many jobs go unfilled. 28 Oct. 2015. <http://www.wsj.com/articles/ small-business-owners-work-to-fill-jobopenings-1404940118>.

Royal Horticultural Society. 2015. Horticulture matters. 23 Oct. 2015. <https:// www.rhs.org.uk/education-learning/ careers-horticulture/horticulturematters $>$.

Rubatzky, V.E. and M. Yamaguchi. 2012. World vegetables: Principles, production, and nutritive values. 2nd ed. Springer, New York, NY.
Siegel, K., M.K. Ali, A. Srinivasiah, R.A. Nugent, and K.M. Venkat Narayan. 2014. Do we produce enough fruits and vegetables to meet global health need? 23 Oct. 2015. PLoS One 9(8):el04059.

Smith, B. 2014. Don't let your children grow up to be farmers. 28 Oct. 2015. <http://www.nytimes.com/2014/ $08 / 10 /$ opinion/sunday/dont-letyour-children-grow-up-to-be-farmers. html?_r $=0>$.

Stone, G., J. Coutts, M. Casey, and A. Coutts. 2005. Strategy to attract young people to horticulture. Acta Hort. 672:339-345.

U.S. Department of Agriculture. 2009. Census of horticultural specialties. 28 Oct. 2015. <http://www.agcensus.usda. gov/Publications/2007/Online_ Highlights/Census_of_Horticulture_ Specialties $/>$.

Wandersee, J. and E. Schussler. 2001. Toward a theory of plant blindness. Plant Sci. Bul. 47:2-9. 29 Oct. 2015. <http:// www.botany.org/bsa/psb/2001/ psb47-1.pdf>. 